\title{
USOS E FUNÇÕES DO PARQUE JARDIM DOS NAMORADOS (SALVADOR-BAHIA)
}

\author{
TRINDADE, Maria Luiza Rabelo Dias
}

Engenheira. Psicóloga. Especialista. Professora do Departamento de Ciências Exatas e da Terra da UNEB (Universidade do Estado da Bahia).E-mail:mtrindade@uneb.br

\section{CUNHA, Rita Dione Araújo}

Engenheira. Doutora. Professora do Departamento de Tecnologia Aplicada a Arquitetura da Faculdade de Arquitetura da Universidade Federal da Bahia. E-mail: ritadi@uol.com.br

\section{RESUMO}

Este artigo considera a paisagem a partir do exame dos elementos naturais, socioculturais e construídos por entender que a cidade constitui parte da natureza. Aponta-se para as funções do espaço livre público no tecido urbano, focalizando o bairro e as suas influências no quotidiano dos usuários. Considera algumas referências conceituais e discuti essas questões, a partir da análise do exemplo concreto de um espaço público, Parque Jardim dos Namorados, situado na orla marítima de Salvador na qual há intervenções de requalificação em curso, no bairro da Pituba. Mostra o processo de construção do espaço no final da década de 1960, as transformações deste espaço livre público e da paisagem do entorno e a situação atual. Aborda as atividades de lazer desenvolvidas pelos usuários. Inclui as festas religiosas e profanas. Relaciona a reforma deste espaço em 1999 ao projeto de reestruturação da orla marítima de Salvador e ao retorno dos usuários ao Parque.

\section{Palavras-chave: Qualidade ambiental urbana, espaço público, parque urbano.}

\begin{abstract}
S
This article considers the landscape from the examination of the elements natural and constructed by understanding that the city constitutes part of the nature. Show the functions of the public space in the city, the influences the district in the diary users. Some conceptual references are considered and argue these questions, from the analysis of the example concrete of a public space, Parque Jardim dos Namorados, situated in Salvador's seafront has been considered in the recent innovation operations, the district of the Pituba. It shows the process of construction of the space in the end of the decade of 1960, the transformations of this public free space and the landscape of round and the current situation. It approaches the activities of leisure developed by the users. Include diverse parties. Relate the reform of this space in 1999 to the project of reorganization of the Salvador's seafront and to the return of the users to the Park.
\end{abstract}

Key words: Urban ambient quality, public space, urban park.

\section{Introdução}

Está se processando no Brasil, a ocupação de áreas pouco favoráveis para grandes empreendimentos imobiliários, ocorrendo alterações na legislação de uso do solo, visando romper com as barreiras à expansão imobiliária. Em Salvador a paisagem urbana dos bairros da Pituba vale do Camaragibe e a região que compreende a orla marítima estão apresentando modificação de uso e funções de seus espaços que contribuem para o desequilíbrio ambiental e provoca conseqüências graves no espaço urbano. A acentuada implantação de edificações verticalizadas acarreta problemas como: aumento do numero de veículos, do escoamento pluvial e pressão adicional sobre o sistema de saneamento, além da restrição a circulação de ventos que podem favorecer a formação de ilhas de calor. 
O Parque Jardim dos Namorados, objeto deste estudo, está inserido em uma região de centralidade no tecido metropolitano, no moderno bairro da Pituba, em área de borda com elevado valor paisagístico e ambiental.

\section{Espaços públicos}

A definição de espaço é multifacetada e empregada em diferentes disciplinas e contextos. Duarte (2002, p.60) forma o conceito de matrizes espaciais com os três elementos: espaço, território e lugar. Afirma que" no espaço os fixos e fluxos serão considerados num campo de possíveis, encontram-se os sedimentos das significações, porem ainda sem as significações (ou se tornaria lugar) e de qualquer hierarquia (ou se tornaria território)", indicando o espaço não como algo puro ou absoluto e sim construído. Considera o lugar mais próximo da experiência enquanto o território é fundamentalmente simbólico.

Gomes (2002) busca compreender o espaço público na cidade contemporânea, baseandose em estudos de caso no Brasil, França e Canadá. Vê o espaço público como um conjunto indissociável das formas físicas com as práticas sociais e acrescenta "(. .).o lugar físico orienta as práticas, guia os comportamentos, e estes por sua vez reafirmam o estatuto público desse espaço". (GOMES, 2002, p. 163 -164). Relaciona as dimensões políticas e sociais de uma esfera pública urbana aos aspectos formais e estruturais dos espaços públicos "concretos". Emprega a acessibilidade como elemento articulador destas dimensões por esta se encontrar vinculado à demarcação dos territórios urbanos contrapondo uma dimensão simbólica à concretude física dos espaços públicos.

Alem da acessibilidade Sennet (1997) diferencia o espaço público do espaço privado opondo a extimidade em oposição à intimidade. A primeira, diz Sennet (1997), possibilita o encontro sem que induza a compulsão da intimidade ou de uma suposta identidade profunda entre os presentes.

Macedo (1995, p.20-21) define espaços livres como "todos aqueles não contidos entre as paredes e tetos dos edifícios construídos pela sociedade para sua moradia e trabalho.", incluindo ruas, praças, pátios, parques, jardins e terrenos baldios, são os espaços livres de edificação. Os espaços livres são classificados pelo autor nos seguintes tipos:

- Espaços Verdes - Corresponde a área urbana coberta de vegetação e que tenha valor social.

- Área Verde - Refere-se a qualquer área onde exista vegetação

- Áreas de Lazer - Consiste em espaços livres destinados ao lazer ativo. e/ou lazer passivo. Observa que as áreas públicas para lazer são denominadas áreas verdes, independente de haver vegetação ou não.

- Área de Circulação - Engloba a grande maioria dos espaços livres de edificações de propriedade pública (no caso todo o sistema viário) e parte do sistema privado de espaços, tais como vilas e sistema viário de condomínios.

\subsection{Parques urbanos}

Os parques urbanos cumprem, entre outras, importantes funções de lazer para a população. Os parques existentes no século XIX e inicio do século XX no Brasil, afirma Sakata (2002), eram estruturados visando ao passeio contemplativo das elites brasileiras. No século XX a população urbana aumenta, em conseqüência da industrialização e especulação imobiliária. A partir desse contexto histórico observa-se o movimento denominado Reform Park (1900 até 1930) a partir do qual, de acordo com Niemayer (2002), ocorre a integração das classes populares ao uso dos parques incluindo tambem os adultos, alem dos jovens e crianças. Niemeyer observa que os parques passam a ser oferecidos em áreas mais densas da cidade e a ser utilizados a qualquer tempo inclusive á noite. A prática do lazer ativo, os jardins de areia e equipamentos infantis 
passam a ser utilizados afirma Niemayer contrapondo-se ao lazer passivo que predominava nos parques e jardins na fase anterior.

Os parques apresentam conceituações diversas. A paisagista Kliass (1993, p.53) classifica os parques em:

- Os parques urbanos são espaços públicos com dimensões significativas e predominância de elementos naturais, principalmente cobertura vegetal, destinados à recreação.

- Os parques de vizinhança atendem num raio máximo de 500 metros sem transito intenso, de forma que as crianças de até 10 anos de idade possam freqüentá-los cotidianamente. Apresentam pequena infra-estrutura de lazer e esportiva.

- Os Parques de bairro destinam-se a recreação ativa de jovens de 11 a 24 anos e a recreação passiva. Seu raio de atendimento é de mil metros.

- Os Parques setoriais destinam-se a recreação ativa e passiva de toda população do município com equipamentos para utilização em fins de semana, com raio de atendimento de cinco mil metros.

O espaço público atualmente, afirma Oliveira (1995), sofre um esvaziamento e desqualificação crescente. Para Oliveira o desafio atual consiste no estimulo ao uso dos espaços públicos incluindo as necessidades físicas e psicológicas que os diferentes usuários possam apresentar visando propiciar a existência de espaços públicos bem qualificados.

Macedo (1995) define qualificação como a possibilidade de apropriação que o espaço permite ao seu público usuário, a qual permitirá aceitação social e manterá por mais tempo sua identidade morfológica.

No caso dos espaços públicos, o uso indicará "a sua obsolescência (pelo baixo nível de apropriação) ou sua estabilidade e durabilidade (pelo alto poder de atração e continuidade de circulação e utilização pelas pessoas)." CUNHA (2002, p. 44).

Gouveia (2001) relaciona a qualidade ambiental a cobertura vegetal urbana por que alem de contribuir na melhoria das condições climáticas, é revestida também de valores estéticos, culturais, históricos e paisagísticos.Considera tambem a praia e o mar elementos importantes são para a qualidade de vida nas cidades litorâneas, mesmo com o comprometimento ambiental decorrente da polvição e tendências a privatização das praias por empreendimentos diversos tais como: hotéis, clubes, condomínios, portos e loteamentos. Os parques urbanos que se localizam na orla destas cidades constituem-se assim em relevante opção de lazer para a população, por associar alem da acessibilidade, elevado valor paisagístico e cultural.

\section{Espaços públicos e lazer em Salvador}

O lazer atualmente aparece de múltiplas formas, observa-se que adquire diferentes significados para a sua pratica em função do contexto econômico e social.O aumento da longevidade e do tempo livre da população, alem da verticalização que está ocorrendo atualmente, resulta numa demanda crescente de espaços livres.

No Brasil, segundo Melo (2003), o acelerado processo de urbanização, a partir da década de 80, levou o planejamento urbano a considerar a permanência ou criar áreas livres e de lazer com o estabelecimento da lei nacional de parcelamento do solo, a partir da qual, o loteador passou a ter obrigação de entregar os lotes em conjunto com outros benefícios, entre eles praças e áreas livres e verdes, consideradas como "áreas comuns do povo".

O plano diretor da orla marítima de Salvador de 1973, já torna explicita a intenção de transformar Salvador num grande pólo turístico nacional. Atualmente as indústrias do turismo e do lazer compõem um setor importante na economia soteropolitana, tais setores respondem pela 
circulação de grandes somas monetárias, em decorrência do simbolismo que envolve o "produto Bahia". (PINTO, 2001).

Salvador conta com muitas áreas de recursos naturais tais como, as praias e ilhas, que constituem áreas de lazer público, porem se faz necessário a construção e manutenção de espaços públicos construídos para tal fim, uma vez que a população de Salvador possui o hábito de empreender atividades lúdicas ao ar livre. Atualmente Salvador possui 178 praças e 68 parques públicos (PDDU - 2002) e até pouco tempo atrás se encontravam, sem manutenção, necessitando de reformas ou intervenções para recuperar funções e espaço físico. A administração municipal em parceria com o governo do estado da Bahia, principalmente na década de 90, passou a investir em áreas públicas. Neste período em Salvador, foram recuperados grandes espaços públicos abertos, implantados novos parques e áreas de lazer, destacando-se: Jardim Zoológico (1993), Parque do Abaeté (1994), Parque de Pituaçu (1994), Parque do Costa Azul (1997), Dique do Tororó (1998), Parque de Esculturas do Unhão (1998), Jardim dos Namorados (1999), Praça da Sé (1999), Parque do Aeroclube (1999). (SOUZA, 2000). Indicando a importância de tais espaços públicos não só para incrementar o turismo e tornar Salvador uma cidade competitiva e através do "city marteking" atrair investimentos para a região metropolitana, mas também para a própria população baiana que por demandar por áreas de desporto e lazer em geral torna-se a principal usuária destes espaços.

\section{A evolução urbana do Parque Jardim dos Namorados e do entorno}

\subsection{Origem e desenvolvimento do bairro da Pituba}

A prefeitura divide a cidade de Salvador em regiões administrativas. $\bigcirc$ bairro da Pituba está localizado na Região administrativa (RA) VIII mostrado na figura 1.

O parque Jardim dos Namorados está localizado na orla atlântica, no bairro da Pituba. Segundo o PDDU (Plano diretor de desenvolvimento urbano) de 2002 é um parque de recreação, situado em zona de borda em zona excluída de assentamentos, conforme a figura 1. A Pituba tem como ais próximos o Costa Azul e Boca do Rio.

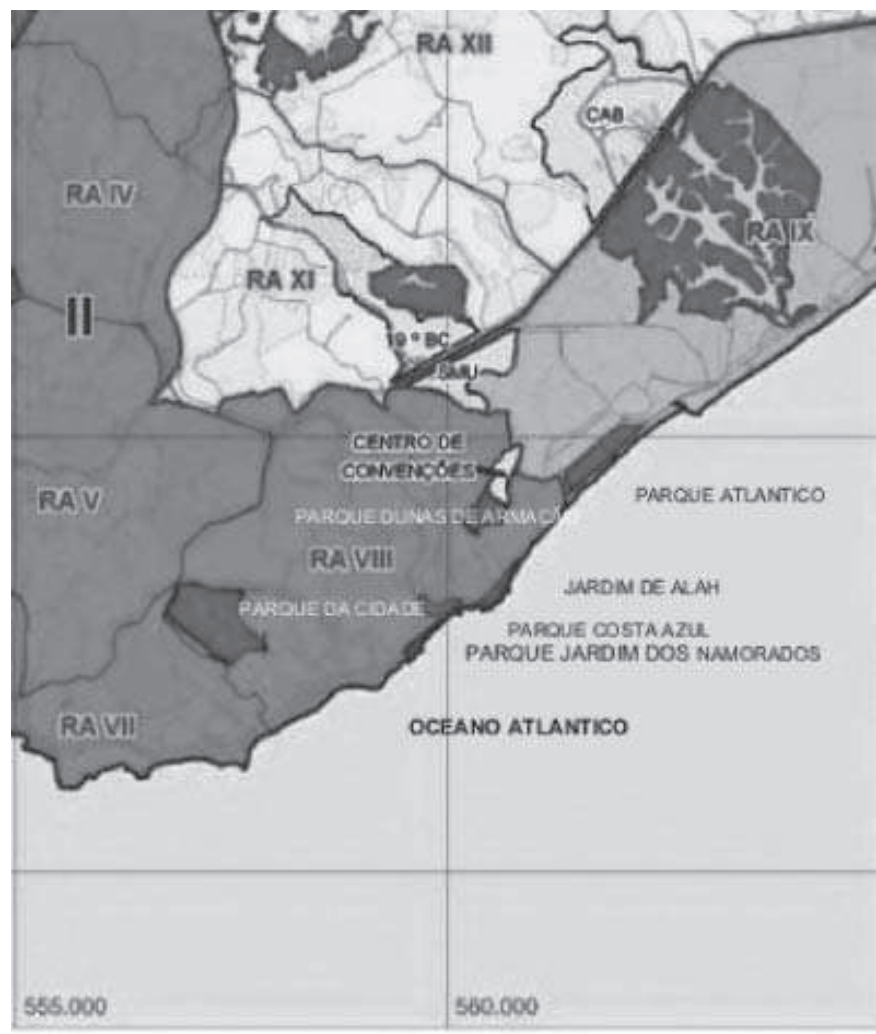

Figura 1: Localização do bairro da Pituba (região administrativa viii)

Fonte: pddu 2002 pr a 64.1

Fonte: Elaboração da autora (sem escala) 
O bairro da Pituba resultou do loteamento da fazenda Pituba, que significa, "sopro forte" em tupi. (SAMPAIO, 1999) No inicio do século a Pituba se constituía numa área periférica ao núcleo urbano de Salvador, a partir do final da década de 1960, houve uma descentralização do antigo núcleo terciário- Comércio e bairros históricos da cidade alta e centralização na nova área do vale do Camaragibe.

O bairro Pituba originou-se de um projeto de loteamento do solo da fazenda Pituba, em 1919, porem a aprovação do projeto de loteamento denominado "cidade da Luz" só ocorreria em 1932. A consolidação do bairro, no final da década de 50, foi dinamizada com a implantação da Petrobras, seguida do pólo petroquímico de Camaçari. (ANDRADE, 2003).

No primeiro plano de urbanismo, encomendado pela prefeitura municipal para Salvador, o EPUCS (Escritorio do Plano de Urbanismo da cidade de Salvador

realizado entre 1943 a 1947, a Cidade Luz na Pituba era considerada como "zona residencial satélite". (VASCONCELOS, 2002).

Ao final dos anos 50, Lima (1985 apud Andrade, 2003, p.85), caracterizou a área da Pituba: como um vasto campo, quase despovoado, tendo, alguma casa de recente construção e muitas casas de palha, moradas de pescadores, seus primeiros habitantes. Havia poucos edifícios, de três andares, no máximo. Predominava ampla plantação de coqueiros de elevada altura, que povoavam colinas e vales. A Fazenda Pituba, tinha por fonte de exploração o coqueiral, que se espalhava por muitos quilômetros ao longo da costa, e para o interior, atingindo o bairro de Brotas.

Entre 1956 e 1958 foi aprovada a ampliação do loteamento Cidade da Luz, na Pituba, numa área de 99 hectares." (VASCONCELOS, 2002).

O ano de 1968 marca a lei de Reforma Urbana, a partir da qual, foram alienadas terras urbanas. Neste contexto influenciou a futura inserção da Pituba no tecido metropolitano a construção pavimentada como as avenidas Antonio Carlos Magalhães e Tancredo Neves. (ANDRADE, 2003), sendo que esta permitiu a ligação entre a área do Iguatemi e a avenida Paralela (SCHEINOWITZ, 1998).

Excluindo-se a concentração do Shopping Center Iguatemi (1975), apesar da diversidade de atividades terciárias, em 1976, havia na zona da Pituba, poucos estabelecimentos comerciais, o bairro era predominantemente uni residencial. Conforme mostra a figura 02.

\subsection{Origem de desenvolvimento do Parque Jardim dos Namorados}

A ocupação do Parque Jardim dos Namorados está vinculada à ocupação da Orla marítima pela população mais abastada, e a presença prévia de colônias de pescadores que foram sendo deslocados para áreas mais distantes na medida em que ocorria a expansão urbana.

Após uma epidemia de cólera em 1855, em Salvador, a população passou a tomar banhos salgados que curavam. O Rio Vermelho, então aldeia de pescadores tornou-se local preferido dos veranistas, que transferiram os pescadores para a Pituba (A TARDE, 06/01/1983, p. 3).

$\mathrm{Na}$ área onde está hoje o Parque Jardim dos Namorados, havia a invasão do Bico de Ferro, nome de um bar bastante freqüentado do local. A invasão inicialmente era ocupada por pescadores e foi paulatinamente invadida por uma população de renda média e alta que lá construiu casas de veraneio. (CORREIO DA BAHIA, 09/02/1999, p.2).

O prefeito, Antonio Carlos Magalhães (ACM), em 1969, determinou a demolição de cerca de 300 casas construídas na área do Bico de Ferro. (CORREIO DA BAHIA, 09/02/1999, p.2)

(...) A luta começou em 1962. ACM em 1967 determinou a demolição de 250 casas de luxo e impediu a construção de mais 50, num dos casos mais rumorosos da época (...) Na manhã de 
29/11/1967 dia em que foi deflagrada a "operação Bico de Ferro" foi iniciada a derrubada de imóveis com ACM à frente. Houve protesto dos proprietários dos imóveis e aplauso da população. (....) Após a demolição a prefeitura iniciou o trabalho de urbanização da área construindo estacionamento, quadras de esporte área de recreação infantil, rinque de patinação pista de aeromodelismo com belvedere. (CORREIO DA BAHIA, 09/02/1999, p.2).

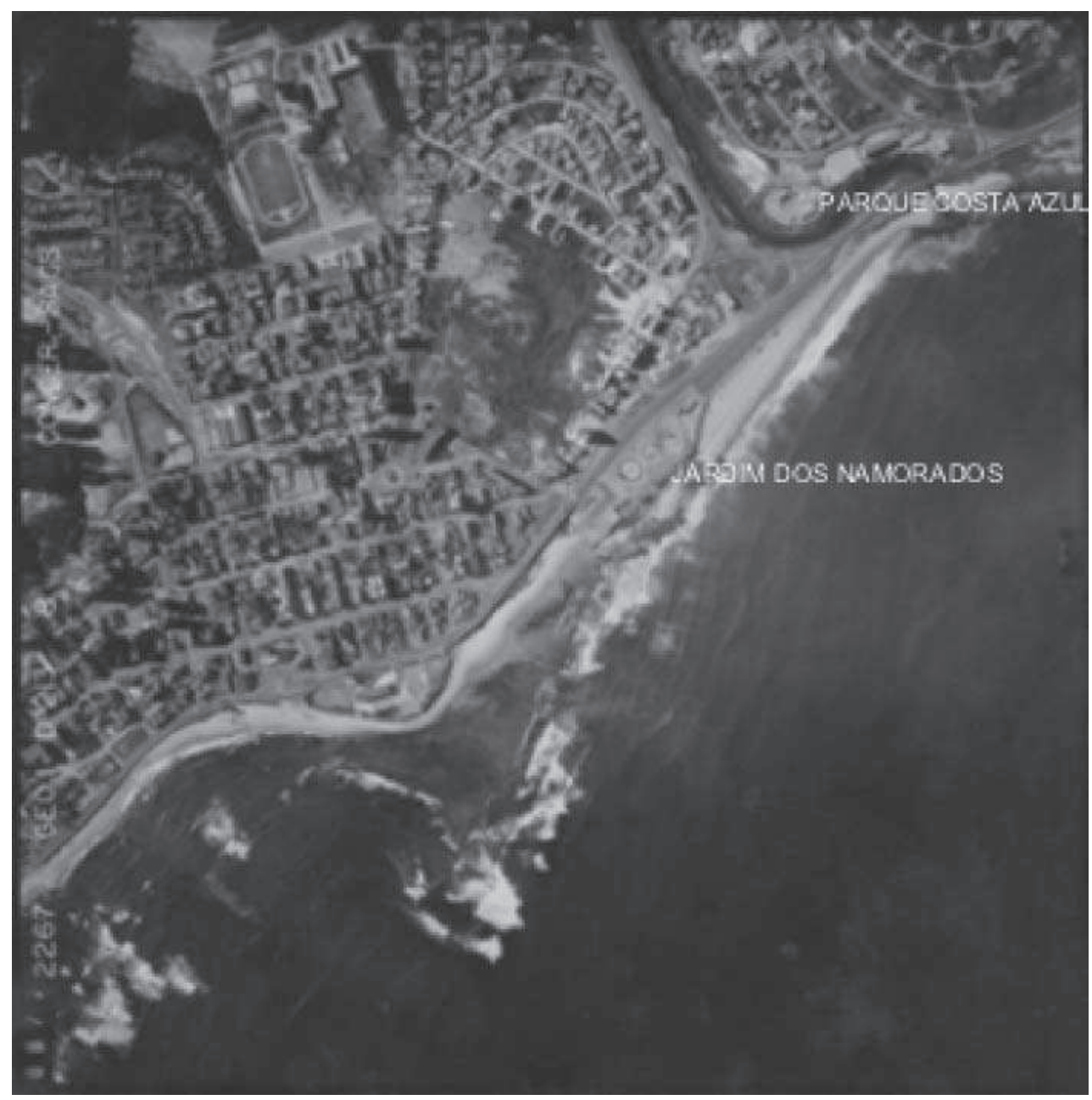

Figura 2: Vista aérea da Pituba, Parque Jardim dos Namorados - 1976

Fonte: CONDER. Elaboração da autora (sem escala)

(...) "parque de estacionamento, quadras para prática de esportes, áreas para recreação infantil, um pergolado que oferecerá sombra, (....)" todas as palmeiras existentes no aprazível local serão aproveitadas para compor a paisagem, enquanto o ajardinamento com características singulares completará a urbanização. (...) foram usadas arenito para base do solo estabilizado (60 mil m3) e 100 mil m3 de barro para preparar jardins e áreas verdes. (A TARDE, 8/01/1969, p.5)

Tem se inicio na década de 70, o processo de segregação mais acentuado da população com a expulsão das invasões da orla marítima e a ocupação do "miolo", região entre a Baia de Todos os Santos e a orla atlântica, pelos "favelados". Neste período (...). ACM derrubou não só as casas do Bico de Ferro, mas também invasões de Ondina, Rio Vermelho e Boca do Rio, todas em terrenos da marinha. (CORREIO DA BAHIA, 09/02/1999, p.2).

A inauguração do Jardim dos Namorados ocorreu no dia 31 de março de 1969, comemorando os 430 anos da cidade e os cinco anos da "revolução", golpe militar de 1964, pelo então prefeito Antonio Carlos Magalhães, na mesma data foi também inaugurada a Avenida Antonio Carlos Magalhães. 


\subsubsection{Lazer}

No século XVII foi construída uma capela de taipa com uma imagem de Nossa Senhora da Luz trazida de Portugal. Em 1954, o então proprietário da fazenda Pituba -Joventino Silva - fez construir no seu terreno a atual igreja, deslocando a construção em relação à antiga capela alguns metros para o norte. Em julho de 1960 foi erigida a paróquia de Nossa Senhora da Luz da Pituba.

A festa da Pituba, em louvor a Nossa Senhora da Luz, teve na década de 70 seu auge, quando autoridades, turistas e moradores do local participavam da lavagem conforme mostra a figura 03, sendo a festa mais longa do calendário de festas populares da Bahia. Alem das novenas, alvoradas, parques de diversões e barracas, no domingo havia a procissão terrestre e na segunda a procissão marítima, na qual os pescadores levam a imagem para o alto mar, conforme a figura 04.

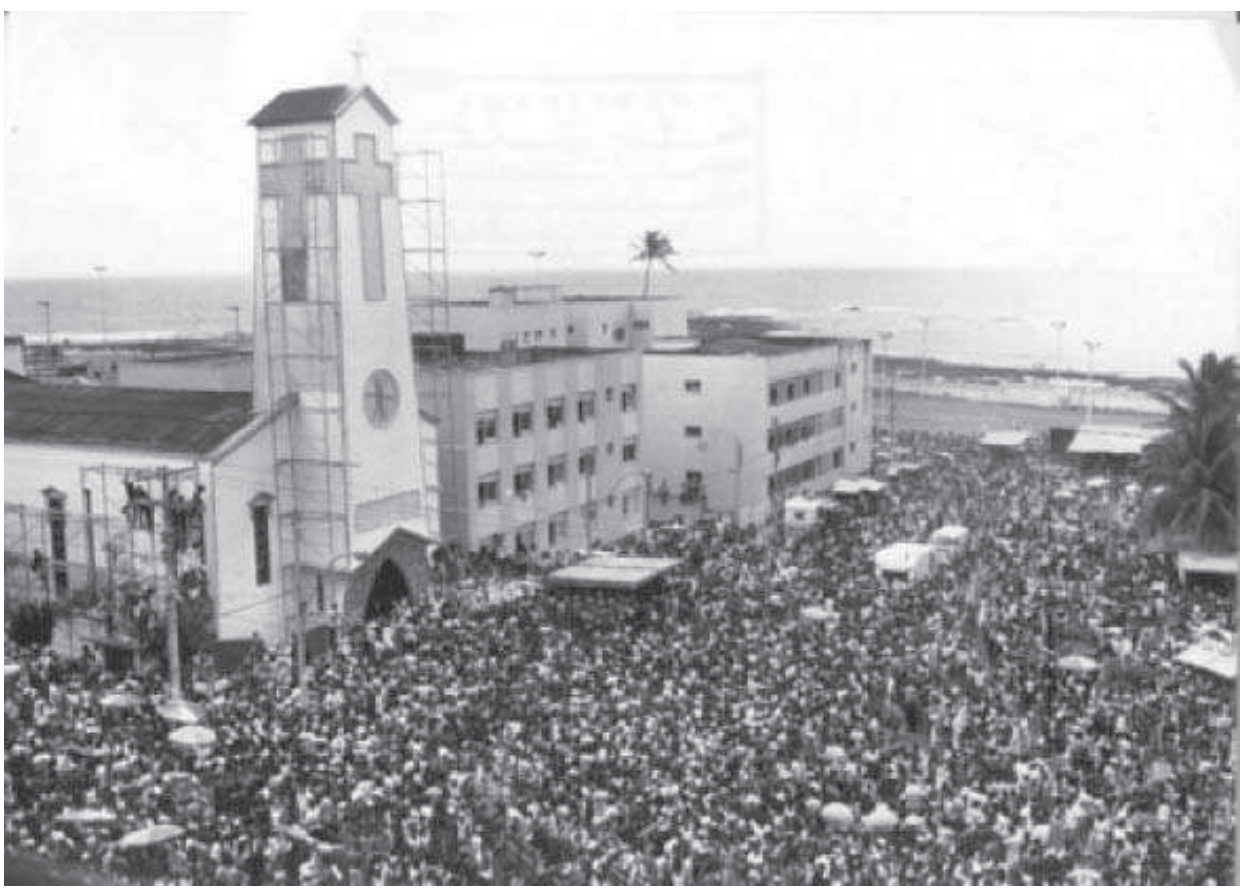

Figura 3: Lavagem da Igreja Nossa Senhora da Luz - Festa da Pituba Fonte: Arquivo fotográfico, jornal A Tarde, 04/02/1979

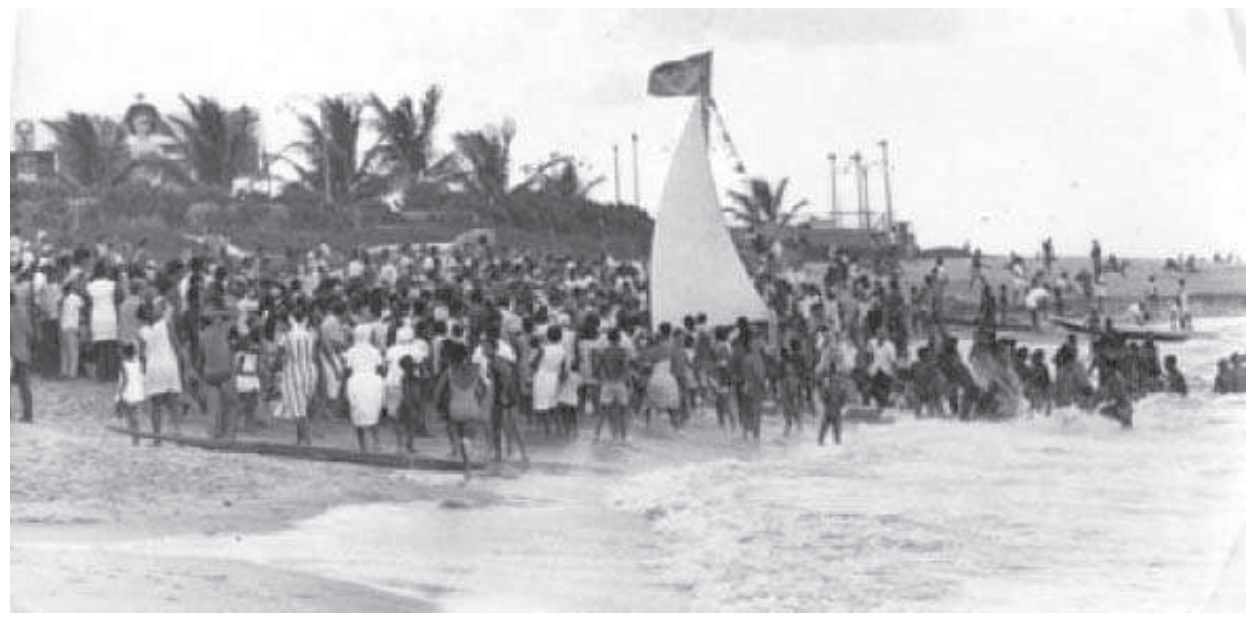

Figura 4: Procissão marítima - Festa da Pituba - [19--]

Fonte: Arquivo fotográfico, jornal A Tarde 
Na década de 80 as autoridades não mais comparecem a festa. (A TARDE, 03/02/1986. p.3), reduziu-se o numero de baianas que participam da parte terrestre e o número de embarcações que participam da procissão marítima, (A TARDE, 12/02/1982, p.5).

O bairro da Pituba, anteriormente de veraneio, torna-se moradia de uma nova classe média que transfere a parte profana da festa para fora do bairro. Em 1985, após a separação da parte profana e religiosa, determinada no ano anterior pelos organizadores da festa, a parte profana passa a ocorrer no Jardim dos Namorados, no estacionamento da churrascaria Roda Viva, sob protestos dos barraqueiros que queriam festa de volta à "praça que é do povo" (Praça Nossa Senhora da Luz, onde se situa a lgreja), e desfilam com cartazes e o slogan "abaixo a burguesia", "mataram a festa da Pituba". (A TARDE, 08/02/1985, p.3). O declínio da festa mostra-se acentuado a partir desta alteração. Atualmente ocorre a parte religiosa e a procissão marítima, porem com participação bastante reduzida, predominando a procissão marítima dos pescadores.

\subsubsection{Uso do solo e vegetação}

A vegetação que caracterizavam a orla da Pituba até a década de 1950, os altos coqueiros, e existiam no Jardim dos Namorados o quais com a intensificação do uso do solo, tornam-se mais rarefeitos, conforme mostram as figuras 05 e 06 da década de 70 e 90.

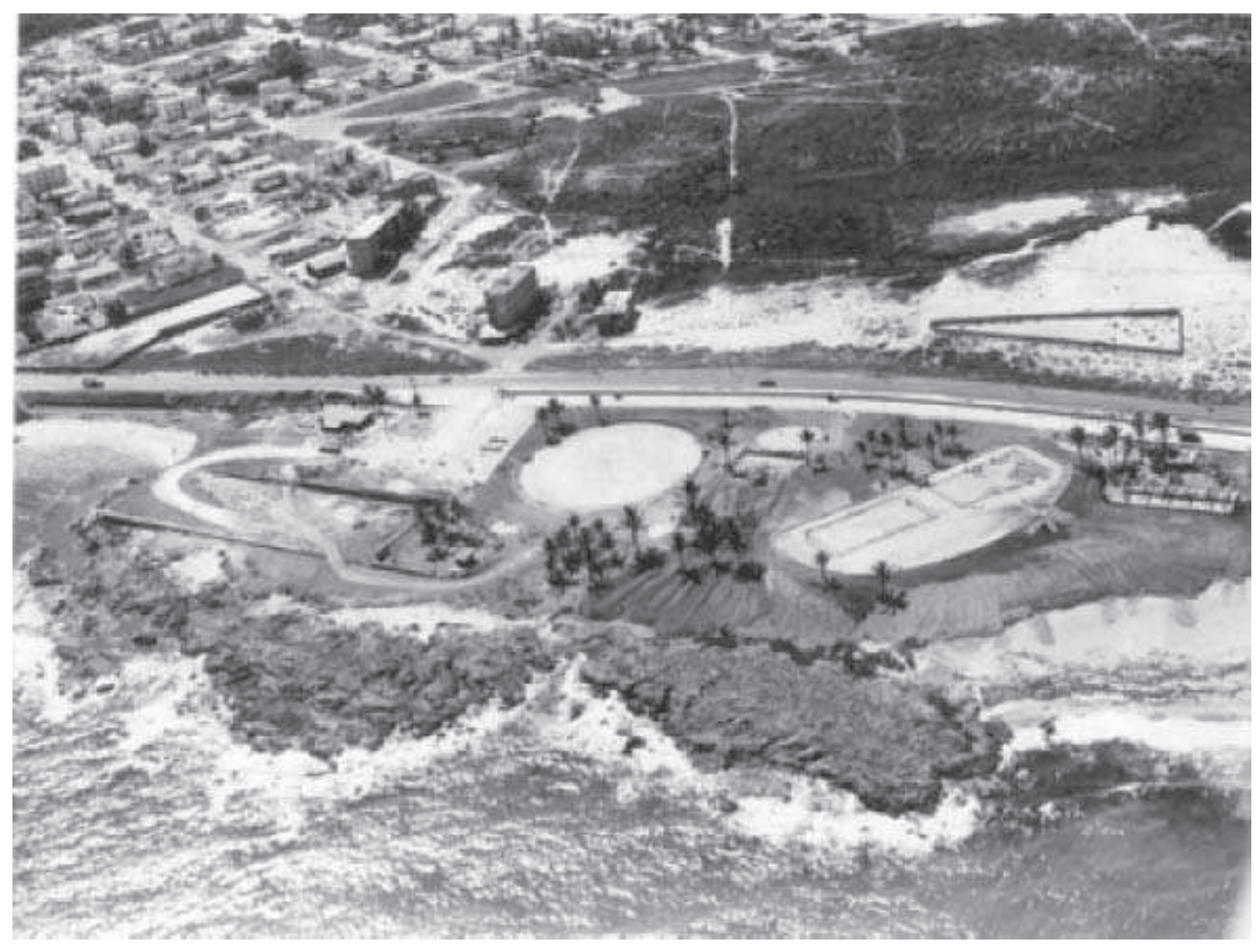

Figura 5: Jardim dos Namorados [197-] (presença de coqueiros)

Fonte: Arquivo fotográfico jornal A Tarde

No final da década de 70 o jardim encontra-se "abandonado" sendo utilizado como depósito de material, destinado as obras de interligação do sistema de esgotamento sanitário da Pituba com o emissário do Rio Vermelho..

Na década de 90 o comercio informal (Kombi e trailers) servem alimentos à noite no Jardim dos Namorados. Na ocasião, as calçadas estavam mal conservadas, com "mato" e os equipamentos esportivos encontravam-se estragados e à noite, o local constituía-se em ponto de prostituição. (A TARDE, 27/04/1997, p.3). 


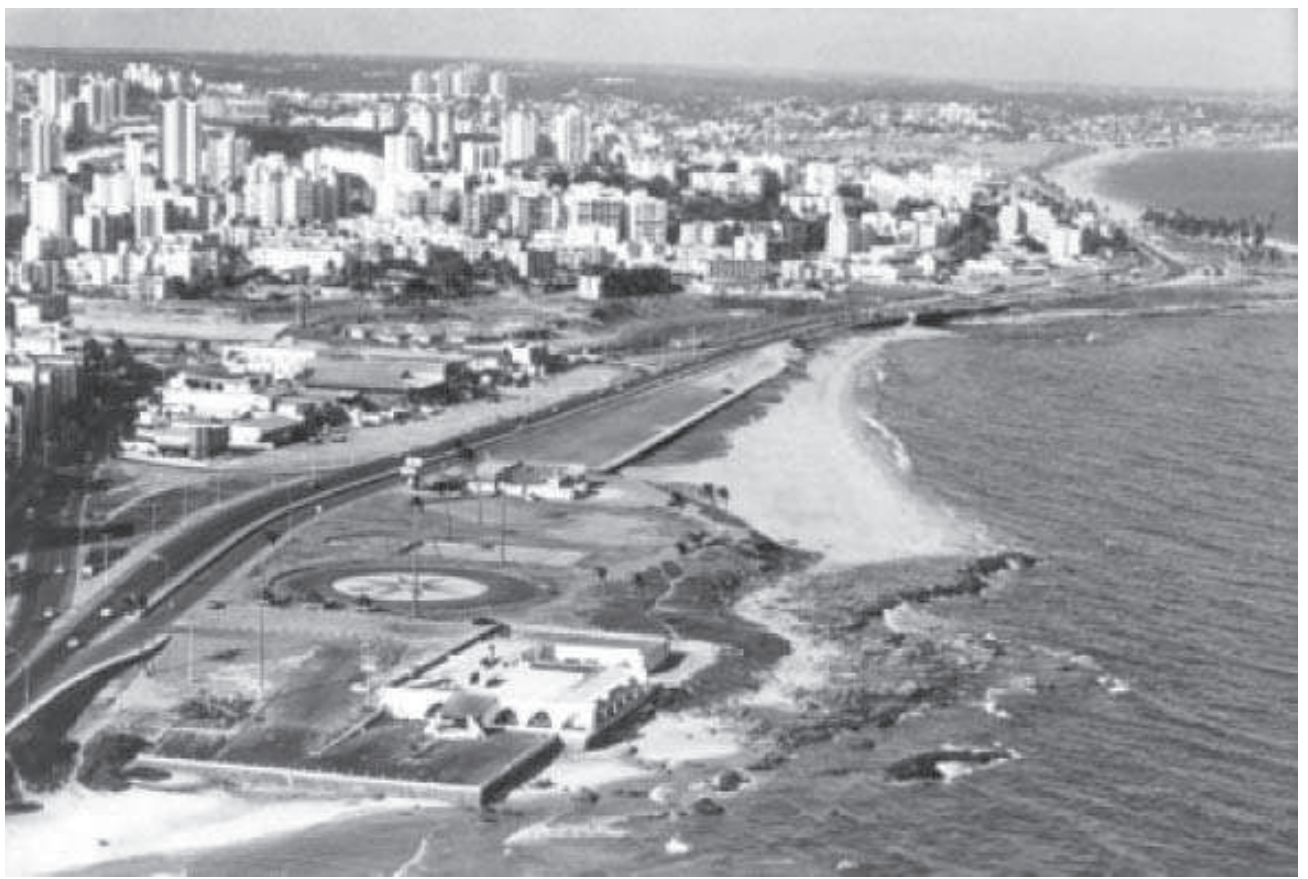

Figura 6: Jardim dos Namorados (menos coqueiros), 1995 Fonte: A Tarde, 02/02/1995

\subsubsection{Reforma do Parque Jardim dos Namorados em 1999}

Em 1998, o Jardim dos Namorados integra um amplo programa da CONDER para a orla marítima de Salvador, com ações que objetivam a recuperação ambiental, reurbanização e implantação de equipamentos de lazer. A recuperação ambiental e urbanística do local foi executada em convenio governo do Estado da Bahia e município abrangendo uma área de $77 \mathrm{~m}^{2}$ e 1,5 km de extensão (A TARDE, 05/03/1998, p.7). A execução deste projeto exigiu a demolição do prédio da churrascaria RODA VIVA em 1998, depois de tumultuado processo judicial. (A TARDE, 03/03/98, p. 5).

A presidente da CONDER, em 1998, Sonia Fontes, declara que o projeto "permite a revitalização do Jardim dos Namorados" e considera o local "ponto de referencia para a Pituba, usado para lazer e grupos de terceira idade que praticam tai chi.". (A TARDE, 1/03/1998, p.6). Afirma que o projeto prevê plantio de coqueiro e vegetação no local. Indica que as barracas de côco existentes há 27 anos no local serão removidas, mas que outras barracas surgirão com sanitário público, os pescadores terão local para a venda. Núcleo de serviços tipo balneário com barracas de praia, 12 decks para barracas, quadras, Posto de SAC (serviço de atendimento ao cliente), Loja 24 horas, Quiosques (caldo de cana, côco e sorvete), ciclovia e calçadão. Estacionamento e aluguel de bicicletas alem de travessias elevadas e redutores de velocidade. (A TARDE, 1/03/1998, p.6)

O projeto do Parque Jardim dos Namorados ainda previa, trailers para informação turística. Seriam instalados equipamentos destinados a "deficientes físicos". Iluminação de mercúrio na praia, além de melhoria da área defronte, colocando mais estacionamentos. $\bigcirc$ parque Jardim dos Namorados iria se constituir, de acordo com Sonia Fontes, em "modelo para a implantação de novos equipamentos na orla". A prefeitura seria a responsável pela administração do local. (A TARDE 23/08/1998, p. 14).

O Parque Jardim dos Namorados foi reinaugurado em 09/02/1999, segundo periódico local, referindo-se a inauguração em 1969 e a reinauguração de 1999 (....) "O Parque Jardim 
dos Namorados era um presente para Salvador de 430 e 450 anos". (CORREIO da BAHIA 10/02/1999, p. 2).

\subsubsection{Situação atual do Parque Jardim dos Namorados}

Os bairros do entorno do Parque Jardim dos Namorados atualmente ainda são predominantemente residenciais, sua população pertence principalmente aos segmentos médio e médio alto da sociedade. $O$ bairro da Pituba sofreu nos últimos anos um grande incremento do padrão de verticalização, passando de residências térreas e de edifícios de até três pavimentos para construções de mais de quinze pavimentos. No bairro Costa Azul e STIEP observam-se também a verticalização, porém de forma menos acentuada, as edificações mais recentes são de oito a dez pavimentos. A figura 7 mostra o Parque jardim dos Namorados e entorno e a figura 8 mostra o Parque Jardim dos Namorados.

O Parque Jardim dos Namorados é interligado ao Parque Costa Azul por uma passarela e ao Jardim de Alah por um "calçadão" e uma ciclovia paralela. É uma área de lazer com funções de circulação: caminhadas, corridas e ciclismo. No entorno "calçadão" encontram-se escolas, academia de ginástica, faculdade e casa de show.

O lazer infantil é desenvolvido no Parque Jardim dos Namorados, principalmente em três equipamentos. No anfiteatro é praticado o lazer que inclui crianças maiores e adolescentes que utilizam bicicletas, patinetes, patins, skates e bicicletas. Há dois conjuntos de equipamentos para ginástica e alongamento. No verão, ocorrem os eventos: feira de artesanato, música e teatro infantil, que são bastante freqüentados

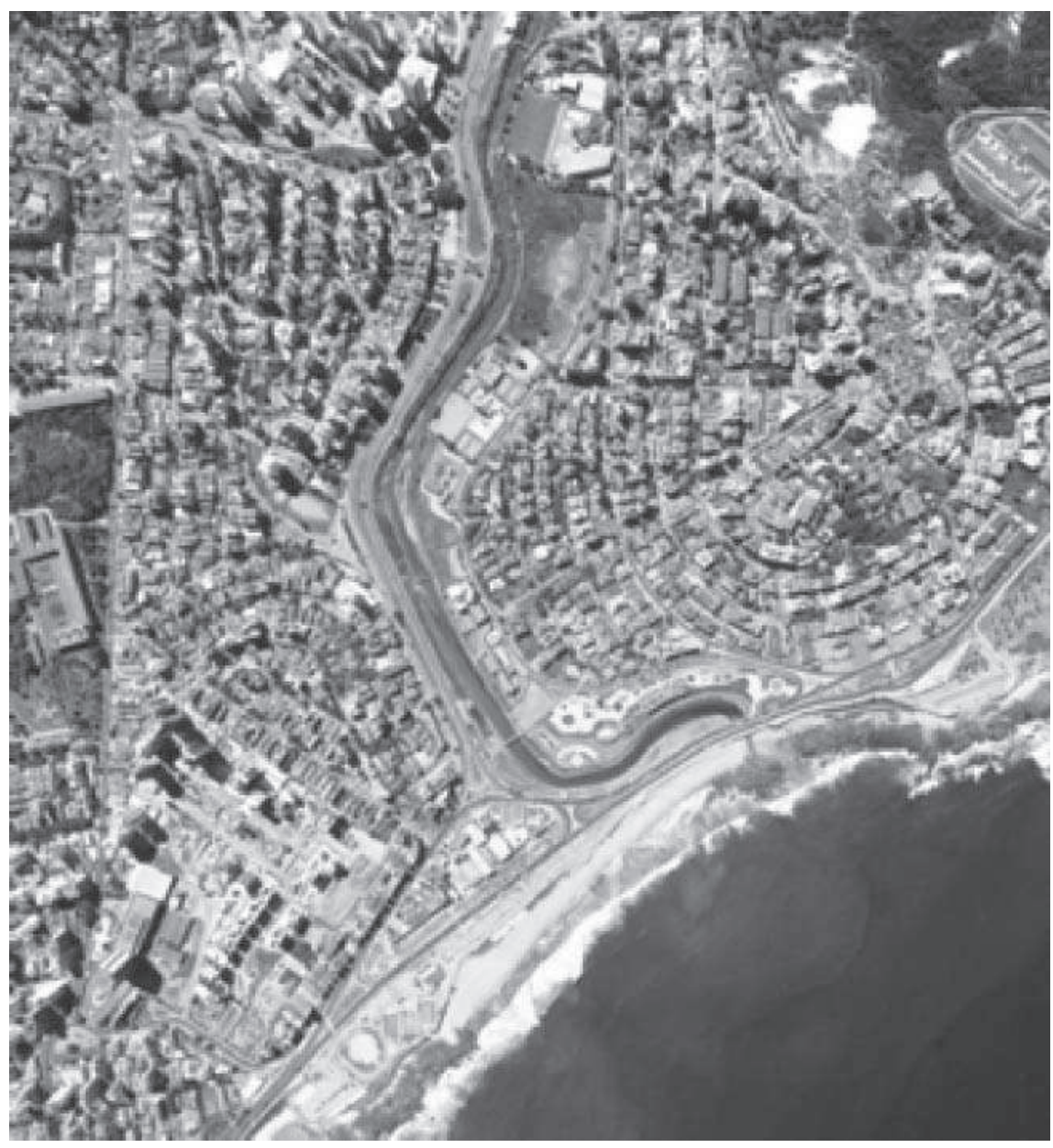

Figura 7: Vista aérea Parque Jardim dos Namorados e entorno, 2002 Fonte: CONDER 


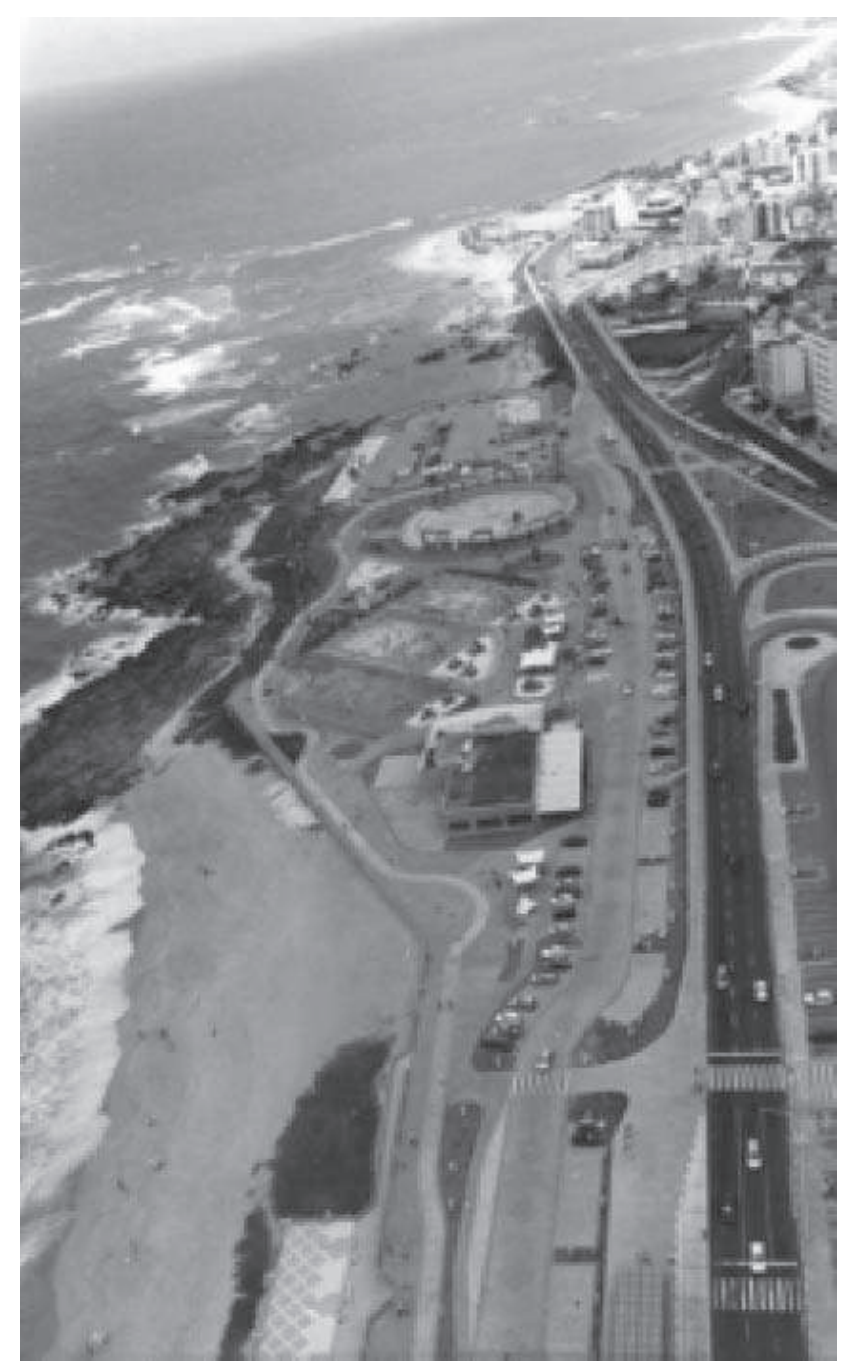

Figura 8: Vista aérea Parque Jardim dos Namorados, 1999 Fonte: A Tarde, 30/1 1/1999

\section{Conclusão}

A atual intervenção no parque Jardim dos Namorados, mesmo tendendo a privilegiar o segmento médio da população dos bairros do entorno, está sendo utilizado por pessoas de classe social e faixas etárias diversificadas, incluindo as de maior vulnerabilidade física as crianças e idosos e sociais principalmente jovens do gênero masculino oriundos do bairro popular da Boca do Rio. Assim o uso mais pronunciado deste espaço, após a intervenção de 1999, contribui para a interação e integridade de um local frágil e privilegiado como a orla marítima de Salvador.

\section{Bibliografia}

ANDRADE, Adriano Bittencourt. Expansão urbana de Salvador: O caso da Pituba. 2003. 229 p. Dissertação (Mestrado) - Instituto de Geociências, Universidade Federal da Bahia, Salvador-BA,, 2001.

CUNHA, Rita Dione Araújo. Os usos, funções e tratamentos das áreas de lazer da área central de Florianópolis. 2002. 353 p. Tese (Doutorado) - Programa de Pós-Graduação em Engenharia de Produção, Universidade Federal de Santa Catarina, Florianópolis, 2002. 
DUARTE, Fabio. Crise das matrizes espaciais. São Paulo: Perspectiva/Fapesp, n. 287, (Coleção Debates) ,2002.

GOMES, Paulo César da Costa. A condição urbana: Ensaios de geopolítica da cidade. Rio de Janeiro: Bertand Brasil, 2002.

GOUVÊA, Irajá. Cobertura vegetal urbana. Revista Assentamentos Humanos, Marília, v. 3, n. 1, p. 17-24, 2001.

JORNAL A TARDE. Salvador, 08 jan. 1969. Caderno 1, seção local, p. 5; Salvador, 12 fev. 1982. Caderno 1, seção local, p. 5.; Salvador, 06 jan. 1983. Caderno 1, seção local, p. 3; Salvador, 08 fev. 1985. Caderno 1, seção local, p. 3; Salvador, 03 fev. 1986. Caderno 1, seção local, p. 3; Salvador, 27 abr. 1997. Caderno 1, seção local, p. 3; Salvador, 01 mar 1998. Caderno 1, seção local, p. 6; Salvador, 03 mar 1998. Caderno 1, seção local, p. 5; Salvador. 05 mar 1998. Caderno 1, seção local, p. 7; Salvador. 23 ago. 1998. Caderno 1, seção local, p. 14.

JORNAL, CORREIO DA BAHIA. Salvador, 09 fev. 1999. Caderno 1, seção Poder, p. 02; Salvador, 10 fev. 1999. Caderno 1, seção Poder, p. 2.

KLIASS, Rosa Grena. Parques urbanos de São Paulo e sua evolução na cidade. São Paulo: PINI, 1993.

MACEDO, Silvio Soares. Espaços livres. Paisagem e Ambiente: Ensaios, São Paulo, n. 7, p. 15-56, 1995.

MELO, Vitor Andrade de. Lazer e minorias sociais. São Paulo: IBRASA, 2003.

NIEMEYER, Carlos Augusto da Costa. Parques infantis de São Paulo - Lazer como expressão de cidadania. São Paulo: Annablume/Fapesp, 2002.

OLIVEIRA, João Martes. Significados do espaço publico. Paisagem e Ambiente: Ensaios. São Paulo, n. 7 p. 57-66, 1995.

PINTO, Roque. A Bahia reimaginada: Como transformar um velho entreposto comercial em um novíssimo produtor de tradições, 2001. Disponível em: <http://www.naya.org.ar/turismo/congreso/ponencias/roque_pinto.htm>. Acesso em: 07 set. 2004.

SAKATA, Francine Gramacho; MACEDO, Sílvio Soares. Parques urbanos do Brasil. São Paulo: Edusp, 2002.

SAMPAIO, Antônio Heliodório L. Formas urbanas: Cidade real \& cidade ideal. Contribuição ao estudo urbanístico de Salvador. Salvador: Quarteto Editora /PPG/ Faculdade de Arquitetura da UFBA, 1999.

SCHEINOWITZ, A. S. O macroplanejamento da aglomeração de Salvador. Salvador: Secretaria da Cultura e Turismo, EGBA, 1998.

SENNET, Richard. Carne e pedra. Rio de janeiro: Record, 2003.

SOUZA, Ângela Gordilho. Mudanças urbanas em Salvador no final do século XX. Bahia Análise \& Dados, Salvador, v. 9, n. 4, p. 53-73, 2000.

VASCONCELOS, Pedro de A. Salvador: Transformações e permanências (1549-1990). Ilhéus: Editus, 2002. 